\title{
O Movimento Afro descendente e as Campanhas de Identidade Étnica Racial na América Latina e Caribe.
}

\author{
Rodrigues, Elza Fátima ${ }^{1}$
}

Recibido: 10 de octubre de /2017 / Aceptado: 2 de noviembre de 2017

Resumo. O presente artigo faz um recorrido diacrônico no processo de articulação das organizações afrodescendentes da América Latina e Caribe para a inclusão das categorias "cor" e "raça" nos censos demográficos nacionais de 2005 a 2013, tendo como contexto as campanhas de comunicação de auto identificação, organizada pelas entidades afrodescendentes na América Latina e o Caribe e os governo nacionais dos países que fizeram parte da ronda dos censos da década de 2010, entre os quais estão Argentina, Brasil, Colômbia, Costa Rica, Equador, Honduras, Uruguai, Paraguai e Peru. O eixo central do artigo é buscar identificar como estes países utilizaram as plataformas virtuais para impulsionar estas campanhas e que mediações comunicativas se fizeram presentes. Para alcançar o objetivo proposto foi utilizada a pesquisa bibliográfica, e a observação não participativa nos blogs, paginas webs dos atores sociais envolvidos no processo.

Palavras chaves: Identidade étnica; censo demográfico; mediações; novas tecnologias.

[en] The afrodescendant moviment and the racial-ethnic identity campaigns in Latin America and Caribbean

\begin{abstract}
The present paper is a diachronic study about the articulation process of Afro-descents organisations in Latin America and Caribbean for the inclusion of the categories "colour" and "race" in the national demographic census from 2005 to 2013. It takes into account the communications campaigns of auto definition, organised by Afro-descents institutions in Latin America and/or Caribbean and the governments of Argentina, Brazil, Colombia, Costa Rica, Equator, Honduras, Uruguay, Paraguay e Peru. The centre line of the paper is to identify the virtual platforms and the communicative mediations used by the abovementioned countries to boost these kind of campaigns. In order to meet the goal, a bibliographic searching was implemented, and also an observation of the participation in blogs and web pages of the social actors involved in the process.
\end{abstract}

Keywords: Ethnic identity; demographic censu; mediations; new Tecnology

Sumário. 1. Introdução. 2. A inclusão da variável cor/raça nos Censos Demográficos. 3. Identidade e mediação comunicativa. 4. Oleada de censos demográficos nacionais e as campanhas de auto identificação. 5. Conclusões. 6. Bibliografia.

Cómo citar: Rodrigues, Elza Fátima, (2017). "O Movimento Afro descendente e as Campanhas de Identidade Étnica Racial na América Latina e Caribe.”, en Mediaciones Sociales, 16, 43-57.

\footnotetext{
${ }^{1}$ Universidade Federal do Pará (Brasil)

rodrigues@gmail.com
} 


\section{Introdução}

A presença dos afrodescendentes ${ }^{2}$ na América Latina e no Caribe tem marcado a história nesta região, mas os dados quantificados desta população ainda são imprecisos. A Comissão de Estados Latino Americanos e Caribenhos (CELAC) ${ }^{3}$, , indica que há mais de 150 milhões de afrodescendentes, cerca de $30 \%$ da população. Deste total cerca de $50 \%$ se concentram no Brasil, $20 \%$ na Colômbia e cerca de $10 \%$, na Venezuela. Significa dizer que, uma entre cada três pessoas na América Latina, é um afrodescendente.

A ausência de dados concretos sobre esta população tem contribuído para sua invisibilidade, que resulta em um alto grau de exclusão social, política e econômica e, consequentemente, a ausência de políticas públicas com fim de superar os baixos índices de desenvolvimento humano e maior participação cidadã. Na América Latina e no Caribe, os afrodescendentes e os indígenas sofrem as maiores taxas de pobreza, e as consequências do racismo cotidiano e do racismo institucional ${ }^{4}$. O Banco Interamericano (BID) e a CELAC identificam em seus informes, além da exclusão, dificuldades em participar plenamente das esferas políticas na sociedade onde vivem. Em 2003, o BID publicou um informe sobre a desigualdade na América Latina e no Caribe, em que destacava que a pobreza na região se aprofundava, afirmando que existe uma estreita relação entre pobreza, desigualdade e cor da pele. (Ferreira \& Walton, 2005:19-20).

Diante deste contexto, organizações afrodescendentes, principalmente nos países com maior presença desta população, como Brasil e Colômbia, iniciaram nos anos 90 um processo político de mobilização, que entre outros objetivos se propunham pressionar os governos a criarem mecanismos institucionais que pudessem dar visibilidade estatística dos afrodescendentes na região, suas reais condições de vida e a partir destes dados, reivindicar a criação de políticas públicas e ações afirmativas para esta população.

Após décadas de reivindicações, em 2001, na III Conferência Mundial de Combate ao Racismo, Discriminação Racial, Xenofobia e Intolerância, instituída pela Organização das Nações Unidas (ONU) em Durban, na África do Sul, estas organizações conseguiram incluir no documento final, uma orientação para que os

\footnotetext{
2 Optamos pelo conceito de afrodescendentes, categoria pactuada por ativistas das organizações negras das Américas nos debates que antecederam a conferencia de Durban, África do Sul, em 2001. Concretamente, recorremos ao conceito trabalhado por Antón (2009:20), que define os afrodescendentes como: "todas as pessoas descendentes da diáspora africana no mundo". "Na América Latina e no Caribe, o conceito se refere a distintas culturas negras ou 'afro americanas', descendentes dos africanos que sobreviveram ao tráfico e o comércio escravista que se deu no atlântico, desde o século XVI até o XIX”. É importante frisar que quando nos reportamos ao Brasil, adotamos o conceito de negro (a) como uma identidade secularmente estigmatizada e historicamente reafirmada de forma positiva pelas organizações negras no Brasil.

${ }^{3}$ Dados apesentados pela Comissão Econômica para a América Latina y o Caribe (CEPAL) (2001:15).

${ }^{4}$ Conceito criado pelos Panteras Negras, Charles Hamilton e Stokely, em 1967, para identificar como se manifesta o racismo na estrutura de organização da sociedade e nas instituições. No Brasil, o Programa de Combate ao Racismo Institucional (PCRI), implementado em 2005, definiu o racismo institucional como "o fracasso das instituições e organizações em prover um serviço profissional e adequado às pessoas em virtude de sua cor, cultura, origem racial ou étnica. Ele se manifesta em normas, práticas e comportamentos discriminatórios adotados no cotidiano do trabalho, os quais são resultantes do preconceito racial, uma atitude que combina estereótipos racistas, falta de atenção e ignorância" (CRI, 2006:22).
} 
governos introduzissem o quesito cor/raça nos censos demográficos nacionais. O artigo 94, do documento final da conferência dispõe a respeito do tema ${ }^{5}$.

E possível, através de uma análise dos resultados aqui apresentados, afirmar que a articulação para a Conferência de Durban inaugurou uma nova forma de mobilização dos afrodescendentes. Não somente pela Conferência em si, mas por toda a caminhada que foi realizada anteriormente, através das pré-conferências, especialmente a das Américas, celebrada em Santigado do Chile, momento em que se estabeleceu uma rede de diálogos com as nações indígenas, organismos internacionais e de cooperação, governos e movimentos sociais, distintos atores sociais aglutinados em uma nova identidade política de articulação: a identidade afrodescendente. Quando um grupo assume uma identidade desde uma postura política, se dá o que Sanzone (2004:30) identificou como etnização, que pode ser caracterizar por uma luta constante contra a identidade essencializada, congelada no espaço e no tempo.

Neste processo de articulação, a comunicação, mas especialmente a Internet e suas distintas plataformas exerceu um papel importante como mediador das construções identitárias com a desterritorialização de tempo e espaço proporcionados pelas novas tecnologias. Um exemplo desta nova forma de ativismo foram as campanhas de comunicação virtuais criadas especialmente para influenciar nos censos demográficos nacionais.

Neste sentido, o artigo descreve e analisa iniciativas como o Blog Afro Censos 2010, organizado por um grupo de expertos de diversos países da América Latina e Caribe que permitiu a socialização e discussões das distintas realidades e identidades afrodescendentes e as aproximações conceituais presentes nas campanhas nacionais de auto-identificação desta população nos diversos países onde foram realizados os censos.

\section{A inclusão da variável "cor/raça" nos censos demográficos}

\subsection{Primeiras iniciativas}

O empenho pela inclusão da variável étnica racial nos censos dos países da América Latina e do Caribe se intensificou no final da década dos anos $90 \mathrm{com}$ a realização de congressos internacionais e uma intensa articulação em torno da presença dos afrodescendentes, o que pode ser identificado como a articulação de espaços transnacionais, compreendidos como “(...) processos que se desenvolvem em uma escala regional ou global, atravessando as fronteiras nacionais, integrando e vinculando comunidades e organizações em novas combinações de espaço e tempo" (Hall, 2006:67).

Nesta nova realidade "transnacionalizada", as organizações buscaram estratégias para combater a invisibilidade da população afrodescendente e

\footnotetext{
5 Artigo 94 "reconhece que as políticas e os programas encaminhados a combater o racismo, a discriminação racial, a xenofobia e as formas correlatas de intolerância devem basear-se em investigações quantitativas e qualitativas em que incorpore uma perspectiva de gênero; nesta políticas e programas se deve ter em conta as prioridades identificadas pelas pessoas e grupos que sejam vitimas ou objeto de racismo, discriminação racial, xenofobia y formas correlatas de intolerância" (ONU, 2001:61).
} 
identificaram como prioridade a necessidade de se obter dados quantitativos fiáveis sobre o número aproximado de pessoas com estas características, uma ação política para exigir que os governos reconhecessem as desigualdades socioeconômicas destas populações, e implantassem políticas públicas com recorte raça/cor, visando superar a exclusão social, econômica e politica deste coletivo.

Mesmo que o auge da mobilização tenha acontecido em Durban, como comentamos anteriormente, esse processo vinha sendo gestado ao longo de anos. Um exemplo desta articulação foi a realização do I Encuentro Internacional Todos Contamos: los Grupos Étnicos em los Censos, (Cartagena, Colombia, 2000), um ano antes de Durban e que contou com a participação de movimentos sociais afrodescendentes e indígenas, universidades, institutos nacionais de estadísticas e fundos de cooperação. $\mathrm{O}$ congresso serviu como troca de experiências entre os países que haviam organizados censos, ou desenvolvido pesquisas sobre as populações afrodescendentes e indígenas, ao mesmo tempo em que debateu as reais possibilidades de incluir ou não a pregunta sobre cor/raça nos questionários censitários.

Entre outras atividades que também podem ser consideradas importantes para identificar o processo de discussão sobre a inclusão da variável étnica racial nos censos demográficos, a realização do Seminário Pueblos Indígenas y Afrodescendientes em América Latina y el Caribe. Información Sóciodemográfica para Políticas y Programas, em Santiago de Chile (2005). Este seminário teve carácter mais técnico. No congresso Censos 2010 y la Inclusión del Enfoque Étnico: hacia una construcción participativa con Pueblos Indígenas y Afrodescendientes en América Latina (Santiago de Chile, 2008) foram debatidos aspectos técnicos e discutidos mecanismos para a institucionalização do tema étnico nos sistemas de coleta de dados de cada país.

Estes três eventos foram significativos, na medida em seus objetivos específicos eram debater a inclusão das populações indígenas e afrodescendentes nos censos demográficos nacionais (Bejarano, 2010). Foram nos eventos de 2005 e 2008 que o conceito de afrodescendente foi reafirmado como uma categoria política e se começou a ser utilizada tanto nos documentos oficiais dos congressos, pelos ativistas, assim como nos documentos produzidos pelos governos.

\subsection{A Conferência de Durban}

Politicamente, o conceito de afrodescendente foi consensual em torno da Conferência de Durban. Um exemplo da construção desta identidade étnica transnacional ficou explicita na fala do ativista Romero Rodrigues, na Conferência preparatória das Américas, em Santiago, em 2000: "entramos negros e saímos afrodescendentes". A afirmação pode simbolizar uma ruptura epistemológica. O aparentemente abandono do conceito de "negro", que para muitos ativistas é um conceito negativo, pois traduz a visão do colonizador sobre os africanos que foram trazidos para as Américas e seus descendentes, é suplantado pelo de "afrodescendente", muito embora este conceito em determinados países ainda seja uma identidade imposta, sem muita ressonância identitária e de mobilização, como é o caso do Brasil, em que o conceito de negro foi resignificado pelas organizações 
negras do país e hoje é reivindicado por uma parte destas organizações, que seja incluído no censo demográfico nacional (Sant'anna, 1995).

A articulação das organizações afrodescendentes para a Conferência de Durban pode ser analisada dentro do que Costa (2006:125) conceitua como "contexto transnacional de ação, onde não há uma territorialidade nem uma temporalidade definida".

Com a preparação para Durban, foram fortalecidas estratégias que desde décadas vinham sendo tecidas, com o objetivo de denunciar as condições sócio econômicas e a criação de politicas públicas com recorte racial. A inclusão das categorias raça e cor nos censos demográficos nacionais foi um dos planteamentos mais significativos realizados por estes coletivos nos momentos prévios e posteriores à Conferência.

Durban cristalizou o fortalecimento do processo transnacional do discurso e ações das organizações dos afrodescendentes na América Latino e o Caribe, com desdobramentos políticos, econômicos, jurídicos e culturais. Deu lugar a criação de novos paradigmas para pensar ação destas organizações dentro do conceito de atlântico negro:

“(...) se refere metaforicamente a estruturas transnacionais criadas pela modernidade que se desenvolvem e dão origem a um sistema de comunicações globais marcadas pelos fluxos e trocas culturais entre as populações negras, a partir da diáspora africana" (Gilroy, 2001:30).

O processo desencadeado após Durban logrou que países como Panamá, Venezuela, Argentina, Uruguai e Paraguai incluíssem a variável cor e raça nos censos que realizariam na roda de 2010. Dos 19 países latino-americanos envolvidos na articulação, somente nove países possuíam dados estatísticos sobre os afrodescendentes. Observa-se uma mudança significativa nos censos realizados na Roda de 2010, com a inclusão das categorias de auto identificação étnica racial em países que nunca havia coletado estes dados anteriormente.

\subsection{O Grupo de Trabalho Afrodescendentes Censos 2010}

Visando acompanhar as ações pós Durban, em 2009 foi criado o Grupo de Trabalho Afrodescendentes Censos 2010, durante a realização do Seminário Internacional sobre dados desagregados sobre raça e etnia para afrodescendentes, realizado no Brasil. A criação do grupo acontece durante a Conferência de Revisão de Durban, más precisamente no seminário sobre Etnia e Raça na Ronda dos Censos de 2010, realizada em 2008, no Chile e no Encontro de Gênero e Estatística de América Latina, em Águas Calientes, também em 2008.

O grupo nasceu com a missão de incorporar a variável cor/raça na ronda dos censos demográficos de 2010. Define-se como "um grupo de trabalho de líderes, expertos e expertos afrodescendentes que foi criado com o objetivo de incidir nos institutos de estatísticas para a incorporação de perguntas de auto identificação racial ou étnica que contabilize quantitativamente e qualitativamente aos afrodescendentes da América Latina e o Caribe nos países que participarão da 
Ronda dos Censos de 2010"6. Com base na recomendação derivada da Conferência, que em seu documento final afirma ser necessário que os dados oficiais deem conta da real quantidade e das condições em que vivem os afrodescendentes, para posteriormente serem criadas políticas públicas que incluam estes coletivos em condições de igualdade com outros grupos. $\mathrm{O}$ grupo de expertos buscando socializar as informações, lançou o blog Afro Censos 2010, cujo objetivo e proposta serão explicitados no próximo epigrafe.

\section{Identidade e mediação comunicativa}

\subsection{Blog Afro Censos 2010}

O "Blog Afro Censos 2010, Todos somos afrodescendentes" foi criado em 2009, por um grupo de expertos de diferentes países como estratégia de comunicação divulgar as ações que estavam sendo organizadas nos países que celebrariam os censos nacionais. Tinha como organizadora, Epsy Campbell, ativista do movimento de mulheres da Costa Rica. Para facilitar a discussão e atender os idiomas oficias dos países envolvidos, o Blog apresentava versões em espanhol, inglês e português e estava estruturado com as categorias de busca afrodescendentes, censo, dados por raça e etnia, estatísticas, jornalismo, mulheres negras, racismo, e ronda dos censos.

Em uma entrevista publicada no Blog, a coordenadora executiva do grupo de trabalho Afro descendentes para o censo de 2010, Campbell afirma que "En el plano regional pretendemos generar una nueva conciencia de que los afrodescendientes son una mayoría en la región y que debe ser incorporado en las preguntas que se realizan en los censos. Durante mucho tiempo, la información oficial en muchos países de la región invisibilizó a los y las afrodescendientes" (Blog Afrocensos2010, 2009).

Este blog se constituiu em um espaço de debate sobre os grandes temas que dizem respeito aos afrodescendentes, mediante reportagens, artigos, entrevistas, vídeos foram divulgadas e socializadas informações, pesquisas realizadas por estudiosos, ativistas, instituições nacionais e internacionais; um espaço rico em informações que aproximou as ações das distintas organizações envolvidas neste processo.

As relações políticas entre as organizações com esta identidade sempre existiram, mas foram fortalecidas a partir dos anos 90, particularmente através dos processos para organização da Conferência de Durban. Neste sentido pode-se afirmar que se desenvolveu um processo de reconfiguração, uma nova estratégia de ação nesta região em que as mediações facilitadas pelas novas tecnologias jogaram um papel significativo no sentido de aproximar contextos e realidades tão diversas no que tange a diversidade dos afrodescendentes na região.

\footnotetext{
${ }^{6}$ Véase: https://afrocensos2010.wordpress.com/about/
} 


\section{Oleada de censos demográficos nacionais e as campanhas de auto identificação}

A primeira campanha de auto identificação pensada especialmente para incidir nos censos demográficos foi realizada no Brasil em 1991, por iniciativa dos movimentos negros brasileiros. Com o título Não deixe sua cor passar em branco. Responda com bom censo, "a campanha tinha como objetivo sensibilizar a pessoas a auto declarar-se e, desta forma, contribuir para a construção de indicadores sócio econômico e veicular mensagens positivas, recuperar a autoestima cultural e politica dos afros descendentes" (Sant'anna, 2009:7). Na organização estavam o Centro de Estudos Afro-Asiáticos, da Universidade Cândido Mendes e o Laboratório de Investigação Social da Universidade Federal do Rio de Janeiro.

A iniciativa surgiu a partir do descontentamento, por parte dos movimentos sociais, intelectuais, geógrafos das classificações adotadas pelo IBGE, destacando que era incorreto perguntar pela cor nos censos. Estes segmentos sociais propunham a inclusão da categoria raça e ao invés de constar no censo a categoria preta, substitui-la por negra. Criticavam também a categoria parda por conta da precisão conceitual (Nobles, 2000; Sant'anna, 2009; Bejarano, 2010). Como estratégia de mobilização foram distribuídos folders em todo o país. E de certa forma a campanha conseguiu problematizar a questão racial para que os dados sobre raça e cor se transformassem em uma reivindicação política. Com a realização do censo 2010, a campanha foi relançada. Em este novo contexto social, mediatizado pelas novas tecnologias ela assumiu formatos virtuais distintos, sem uma uniformidade, como havia acontecido em 1991.

Com as resoluções a partir da Conferencia de Durban, como identificamos anteriormente foram retomadas criadas estratégias de comunicação por parte das organizações afrodescendente como o objetivo de incidir nos resultados dos censos celebrados a partir de 2010. Esta junção de censos, titulada Oleada de Censos Populacionais se realizou de 2010 a 2013. Em 2010 foram celebrados em maio no Panamá, outubro na Argentina, e em novembro no Equador. Em 2011, em maio, na Costa Rica, setembro no Uruguai e Venezuela. 2012 foi a vez de Chile, em abril, Cuba, em setembro, Paraguai em outubro, finalizando o ano de 2013, em que Honduras contabilizou sua população.

A seguir serão identificadas as campanhas, os meios de comunicação em que foram veiculadas, as plataformas virtuais as identidades étnicas acionadas e os possíveis resultados alcançados.

\subsection{Primeira campanha: Colômbia 2005}

Em 2005, Colômbia lançou a campanha Las Lindas Caras de Mi Gente Negra, uma iniciativa da Conferência Nacional Afrocolombiana. Mediante um spot de televisão de 60 segundos, também veiculado por YouTube, mostra rostos de crianças, jovens, mulheres e homens como rasgos afrodescendentes que expressam a seguinte mensagem: Yo soy negro, Moreno, Mulato, Zamba. Yo soy afrodescendente. Yo cuento. Palenquero, Raizal, Negra. No final do vídeo, uma jovem fala: Mi gente, em este censo cuéntales: Orgullosamente afrocolombiano. 
O spot foi divulgado em todo o país, principalmente em Cali, Medellin, Cartagena, Barranquilla, Bogoteiá e na região do Pacífico, com forte predominância de negros. Foi a primeira campanha com essa amplitude realizada no país. Os movimentos afros colombianos a consideram um feito histórico, pois rompeu com a invisibilidade destes grupos étnicos. Neste ano, aumentou para $22,6 \%$ o percentual de pessoas que no censo se definiram como afrodescendentes.

\subsection{Censos celebrados em 2010}

\section{Argentina}

Após 115 anos a Argentina não incluía nenhum dado que pudesse identificar qual o número aproximado de afrodescendentes em seu território. Em 2010 a pergunta foi incluída: "¿Usted o alguna persona de este hogar es afrodescendiente o tiene antepasados de origen afrodescendiente o africano (padrem madre, abuelos(as), bisabuelos(as)? Segundo dados apresentados pelo governo argentino, 3\% dos argentinos se auto identificaram como afrodescendentes.

A campanha criada para estimular que a população afrodescendente se auto identificasse foi organizada pelo governo Argentino, através do Instituto Nacional Contra la Disciminación, la Xenofobia y el Racismo, que criou e veiculou um vídeo de 54 minutos com a seguinte mensagem: "- Soy afroargentino. - Estoy orgullosa de ser afroargentina. Soy afrodescendiente. ¿Quieren conocer cuántos y cuántas afroargentinos somos? El día 24 de octubre, el próximo censo nacional nos permitirá saber".

A campanha foi veiculada nos meios de comunicação tradicionais, como rádio, jornais e televisão, mas teve grande divulgação através do YouTube.

\section{Brasil}

Por ocasião da realização do censo de 2010, o governo brasileiro lançou uma campanha oficial nos médios de comunicação (rádio, televisão, Internet) estimulando a todos os brasileiros a auto identificar-se de acordo com as categorias censitárias propostas pelo IBGE. A população foi estimulada a auto se incluir dentro das categorias censitárias. O vídeo lançado pelo governo tinha o seguinte texto: Sou Thais Araújo. Sou negra e a cor da minha pele é preta e esta será minha resposta quando o censo 2010 me perguntar por minha cor. Quando chegar sua vez faça você também o mesmo. Diga que sua cor de pele é branca, preta, parda, ou que você é indígena. Só sabendo quem eres o Brasil poderá atender tuas necessidades e ser um país cada vez melhor. A mensagem atua na perspectiva de estímulo para que todas as pessoas de distintas identidades étnicas/raciais se façam presentes e não somente as que pessoas negras e pardas, como identificamos em outros países. O censo de 2010 por primeira vez o número de pessoas que se declaram preta e parda atingiu $54,7 \%$ da população.

No caso do Brasil, além da campanha institucional, foram desenvolvidas outras iniciativas midiáticas promovidas, principalmente, por organizações afrodescendentes e indígenas. A mediação estruturada a partir das novas 
tecnologias foi o diferencial. Desde 2000, com a criação da rede social Orkut, aconteceu o fenômeno das comunidades virtuais como "Orgulho Negro, Morena não, sou Negra", "Raízes Afrodescendentes" e "Eu sou Afro-brasileiro", trouxeram para o mundo virtual temas que inquietavam, os jovens como o racismo, o preconceito, a valorização da identidade e da cultura afro-brasileira. O debate sobre identidade, as categorias do censo e as campanhas de auto identificação foram temas que ocuparam os espaços virtuais e permitiu que jovens de distintos países pudessem com apenas um clic ampliar sua percepção sobre ser afrodescendente, negro, pardo, preto, indígena, branco.

\section{Equador}

“¿Cómo se considera usted, según su cultura y costumbres? (indígena, afroecuatoriano, negro, mulato, motúbio, mestizo, blanco, otro)".

Com a campanha Familia, identifícate. Orgullosamente afroecuatoriano. Familia, súmate. Afroecuatorianos $100 \%$, Equador desenvolveu uma campanha destinada para os afrodescendentes. $\mathrm{O}$ vídeo inicia com uma mulher negra jovem convidando: "Familia afroecuatoriana: este 28 de noviembre de 2010 es el censo de población y vivienda. Cuando te pregunten: de acuerdo con su cultura y costumbres, ¿usted cómo se identifica?, responda: Orgullosamente afroecuatoriano. De saber cuántos somos depende nuestro desarrollo. Familia, identifícate. Com esta mensagem, Equador mobilizou os afrodescendentes no censo de 2010. A campanha, idealizada e coordenada pela Cooperação de Desarrollo Afro Ecuatoriano (CODAE), foi considerada um êxito por seus organizadores e do governo equatoriano. Os dados alcançados mostram um crescimento no número de pessoas que se auto-definiram como afrodescendentes ${ }^{7}$. No censo de 2000 o percentual foi de 5\%, enquanto que no censo de 2010 este número subiu para cerca de $7,2 \%$ da população.

\section{Panamá}

Panamá levaba sete décadas sem incorporar nenhuma pergunta sobre a identidade étnica racial de sua população. Com a pergunta que contou: " ¿Se considera usted negro colonial / Negro(a) antillano(a) / Negro (a) / Otro (especifique) / Ninguna”. O censo identificou que $9,2 \%$ da população se considerou afrodescendente. Os dados foram questionados pelo Consejo de Etnia Negra e pela ONU, que estimam que esta população represente, no mínimo, a quarta parte dos residentes no Panamá. A campanha foi desenvolvida utilizando a Internet como grande impulsora.

\footnotetext{
${ }^{7}$ Para a Comisión Nacional de Estadísticas para Pueblos Indígenas, Afrodescendientes Ecuatorianos y Montúbios (2008), são considerados afrodescendientes aquelas pessoas que se auto definem como negros ou mulatos.
} 


\subsection{Censos realizados em 2011}

\section{Costa Rica}

“¿Se considera: a) negro, b) mulato, c) blanco ou mestizo, d) outro, e) ninguno?” Foram as categorias presentes no censo demográfico na Costa Rica. Segundo dados divulgados, em 2012, pelo Instituto Nacional de Estadisticas y Censos de Costa Rica (INEC), 7,8\% da população se definem como afrodescendentes, negros e mulatos. No censo de 2000 este número não chegou a 1, 9\%. Não foi realizada nenhuma campanha institucional. A iniciativa de trabalhar o tema foi da Asociación para el Desarrollo de las Mujeres Negras Costarricences, uma entidade do movimento social organizado pelas mulheres negras no país.

\section{Uruguai}

No caso do Uruguai, a pergunta formulada foi: “ ¿Cree tener ascendencia ... a) afro o negra; b) asiática o amarilla blanca, c) indígena, d) otra?”.

Com o lema Mamá África, tiene que ver contigo, Uruguai promoveu campanha de auto definição organizada por UBUNTU, uma organização da sociedade civil. O spot continha a seguinte mensagem: "En el censo 2011 cuando te pregunten por tu ascendência, contesta que "Sí, soy afrodescendiente. La campaña sirve para hacer visibles las condiciones en que vivimos. Con estos datos, el Estado podrá desarrollar acciones que mejoren nuestra calidad de vida. Somos un montón. Mamá África tiene que ver contigo". Mesmo com a campanha, contraditoriamente, diminuiu em 1 ponto percentual o número de afrodescendentes (em 2006 foram contabilizados $9,1 \%$; em 2011, 8,1\%).

\section{Venezuela}

O censo de 2011 foi o primeiro do país a coletar dados sobre o pertencimento étnico racial da população. Com a pergunta: "Según sus rasgos físicos, ascendencia familiar, cultura y tradiciones ¿cómo se reconoce? negro/negra, afrodescendiente, moreno, blanco". Até o fechamento deste artigo não havia sido publicado nenhum resultado sobre censo demográfico realizado naquele país.

\subsection{Censos celebrados em 2012}

\section{Chile}

O censo populacional do Chile perguntou a seus cidadãos: “¿Se considera perteneciente a algún pueblo indígena? Sí / No. Para especificar, em caso afirmativo elija uma de las siguientes opciones: Mapuche, Aymara, Riapa Nui, Likan Antai, Quechua, Colla, Diaguita, Kawesgar, Yagan o Yamana, Otro”. Se observa que não foi incluída nenhuma pergunta sobre os afrodescendentes. Mesmo sem um levantamento específico sobre a população afrodescendentes, o governo do país trabalha com cerca de $4 \%$ da população possui estas características. 
Cuba

A pergunta incorporada no censo demográfico em Cuba teve uma única opção: “¿Cuál es su color de piel? Blanco / Negro / Mestizo / Mulato”. Igual a Venezuela, não foram encontrados resultados sobre o censo demográfico, assim como dados sobre a presença dos afrodescendentes.

\section{Paraguai}

Desde o ano de 1950, Paraguai não incluía uma pergunta relacionada à identidade racial de sua população. Em $2012 \mathrm{fez}$ a seguinte pergunta: “¿Usted o alguna persona de este hogar es afro? ¿Tiene antepasados de origen afrodescendiente $o$ africano (padre, madre, abuelos, bisabuelos...?”.

No censo realizado em 2012, o governo divulgou um vídeo em formato de desenho animado, um diálogo entre dos personagens: “¿Sabías que... en el pasado más de la mitad de la población en Asunción era afrodescendiente? - ¿Y cómo podemos saber cuántos son hoy? - Los censistas están recogiendo cada hogar para ayudarnos a conocer nuestra realidad. - Si sos afrodescendiente, autoidentifícate como tal en el censo 2012. Paraguay sí suma”.

Segundo dados apresentados pelo censo demográfico de 2012, a população afrodescendente no Paraguai é de cerca de 5.000 autodeclaradas e vivem principalmente em torno da comunidade de Emboscada, a quarenta quilômetros do norte da capital, Assunção.

\subsection{Censos celebrados em 2013 e 2014}

\section{Honduras}

Em Honduras, a pergunta foi: “¿Cómo se autoidentifica? Indígena, negro, mestizo, blanco, otro (especifique: ¿A qué pueblo pertenenece (nombre)? Maya- Chorti, Lenca, Miskito, Nahua, Pech, Tolupán, Tawanka, Garifuna, negro de habla inglesa".

No censo, celebrado em 2013, Honduras lançou a campanha: Tengo identidad y confío en el censo de 2013. O video, de 26 minutos, divulgado nos meios de comunicação e na Internet vem com a seguinte mensagem: "Yo soy garifuna. - Por eso vivo mis tradiciones. - Tengo amor por mi territorio. - Vivo orgullosa de mis raíces. Por eso soy orgullosamente garifuna. - Tú cuentas. Uma voz em off finaliza o video: - Por tus derechos y beneficios. Confía en el censo 2013 y participa. Tú cuentas".

Os resultados divulgados pelo Instituto Nacional de Estadisticas (INE) indicam que $0,9 \%$ da população é afro descendente. Foi questionada se dentro deste grupo, foram incluídos os negros ingleses (Amaya, 2007:27) e os garifunas, já que esta categoria identitária foi construída e imposta a partir da conferencia de Durban, que até então era de certo forma inexistente. 
Peru

Em 2007, o censo demográfico realizado no país não fez nenhuma pergunta relacionada aos afrodescendentes. Em 2014, o Ministério de Cultura, pressionado pelos movimentos sociais realizou um estudo especializado sobre a população afroperuana. Poucas informações foram divulgadas sobre este estudo, mas entre os dados apresentados pelo governo, cerca de 3.101 residências, em sete regiões foram pesquisadas. Deste total, $100 \%$ das pessoas entrevistadas têm orgulho de suas descendências africanas. Sobre a campanha de auto identificação dos afros peruanos encontramos um vídeo em YouTube ${ }^{8}$. O vídeo tem a seguinte mensagem:

“- ¿Qué cosa es ser afroperuano?

- Invisibles.

- Yo siento que soy invisible cuando le digo a alguien que existe racismo en Perú y no me cree.

- No me llamo ni morenita, ni zambita, ni morocha.

- Todo lo negros parecen estar vinculados hacia lo negativo.

- Yo no cocino, no bailo. Yo no toco ningún instrumento. Me dicen: ¿cómo puede ser negra? ¿es una negra bamba?

- Hay negros que ya no quieren ser negros.

- No hay color ni marrón, ni moreno, sino negro. Punto.

- Ser afro es alegría, diversidad, herencia cultural, familia, pasión talento, memoria, presente, futuro, dignidad. Es vida. Es ser humano

- No somos invisibles. Somos orgullosamente afroperuanos.

- Aquí estamos. Somos orgullosamente afrodescendientes”.

\section{Conclusões}

A partir dos dados apresentados, podemos concluir que o Blog Afro Censos e as campanhas de auto identificação, pensadas para estimular que mais pessoas se auto declarassem dentro das categorias étnicas raciais ou outras formas de pertencimento, de acordo com os elementos históricos e culturais de cada país, veiculadas principalmente pela Internet, é resultante do processo de mediatização da sociedade, que com a inserção das novas tecnologias, apresentam mudanças nos paradigmas comunicativos. Neste sentido, o artigo identificou que em todos os países em que realizaram os censos demográficos foram desenvolvidas ações de comunicação, sejam elas institucionais ou promovidas pelas organizações da sociedade civil, destacando a necessidade da população afrodescendente não simplesmente ser contabilizados, mas identificada como parte da história destes países, lutando assim contra a invisibilidade social.

Analisando uma das plataformas virtuais criadas para contribuir com o processo, o Blog Afro Censos, criado para divulgação das ações das organizações afrodescendentes e socializar informações sobre esta população, identificamos que mesmo estando disponibilizado em inglês, espanhol e português, o Blog tinha

\footnotetext{
${ }^{8}$ Véase: https://www.youtube.com/watch?v=vfX7AWPzp8E
} 
baixa participação de pessoas que não faziam parte destas organizações. Com conteúdo rico em informações e dados sobre os afrodescendentes, vídeos, entrevistas, publicações de livros e revistas, o formato do blog o deixava muito denso, com muitas informações, que dificilmente uma pessoa jovem e que não tivesse muito envolvida no processo o acessassem de forma sistemática. Por outro aspecto, se formos analisá-lo como uma ferramenta de conteúdos online, pensado para subsidiar, trocar informações e acompanhar o processo dos censos nos países, concluímos que ele atingiu seu objetivo, na medida em que compartilharam muitas informações sobre a história, as reivindicações, os aspetos culturais, as particularidade e semelhanças desta população que ainda em determinados aspectos necessita ser conhecida entre si.

Sobre as campanhas de valorização dos afrodescendentes, não podemos avaliar até que ponto chegou a atingir o público alvo, considerado que em muitos países onde estas campanhas foram desenvolvidas, uma parte considerável da população tem acesso restrito à Internet e às novas tecnologias. Sem embarco, o fato de uma campanha nacional estimulando para que um determinado grupo social, seja chamado a auto identificar-se de forma que resgate a auto estima coletiva deste grupo, revela um aspecto positiva na luta pelo reconhecimento das múltiplas identidades existentes nestes países.

As mensagens, os conteúdos apresentados, as identidades reivindicadas em cada campanha ora identificando-se como uma "família", o caso de Equador; ou "as lindas caras de mi gente negra", em Colômbia; "Mamá África tiene que ver contigo", em Uruguai; ou o chamado "para os afrodescendentes se auto identificarem", no Paraguai; ou ainda como em Honduras, que em sua mensagem estimulava as pessoas que viverem "orgulhosamente suas raízes e sua identidade garifuna", revela aspectos relevantes como a reafirmação positiva, afirmativa de identidades negadas, silenciadas, estigmatizadas como são as afrodescendentes e indígenas nesta região. Outro aspecto importante a ser considerado é que na medida que campanhas como estas se realizam beneficiam não somente os atores sociais envolvidos, mas toda a sociedade, pois a medida que um grupo social é reintegrado de forma positiva na memória coletiva de um pais, os demais grupos sociais são "obrigados" necessariamente a se recolocar nesta história, abrindo espaço para se repensar este pais a não apenas na perspectiva do etnocentrismo, mas da diversidade e da multiculturalidade.

No caso das ações desenvolvidas pelas organizações afrodescendentes, especialmente nas que fizeram parte da Ronda dos Censos 2010, o processo de articulação das organizações afrodescendentes antes e pós Conferência de Durban, na África do Sul, em 2001, trouxe resultados significativos, não somente pela inclusão das reivindicações históricas desta população no documento final da ONU que reconhece que existe uma relação causal entre pobreza e a cor da pele, mas especialmente pelas teias reconstruídas por estas organizações que com a utilização das novas tecnologias, especialmente a internet, ampliaram o debate sobre a identidade étnica racial, especialmente nos países que participaram da Ronda dos censos de 2010 a 2013, objeto de estudo do presente artigo.

Países que nunca haviam incluído as categorias raça/cor nos censos nacionais, nem qualquer instrumento de coleta de dados oficiais sobre a presença dos afro descendentes, ou que depois de décadas incluem nos censos pelo menos uma 
pergunta sobre a identidade étnica racial de sua população, como foi o caso de Panamá que há setenta anos não coletava nenhuma informação sobre os afro descendentes. Argentina há cento e quinze anos. Desde 1950, Paraguai não incluía nos censos estas categorias identitárias.

Sem a mobilização dos afrodescendentes e as resoluções a partir de Durban iniciativas como estas seriam impensáveis. Ainda é cedo para avaliar os impactos das campanhas de auto identificação, mas o fato de estar disponibilizadas nos meios de comunicação, especialmente na internet, nos blogs, nas redes sociais e outras plataformas virtuais, podem influenciar os jovens afrodescendentes, indígenas na construção e (re) elaboração de suas identidades étnicas raciais, contextualizada em suas realidades locais, mas enriquecidas pela possibilidade de deslocamento no tempo e espaço, proporcionado pela mediação estruturada pelas novas tecnologias e as mediações políticas plantear uma nova forma de pensar sobre as identidades afrodescendentes na América Latina e no Caribe.

\section{Bibliografia}

Andrade, M. M. (2012). Negritude em Rede: discursos de Identidade, Conhecimentos e Militância- Um estudo e caso da comunidade Negros do Orkut (204-2011). Dissertação. Brasilia: Universidade de São Paulo.

Antón, J., Bello, Á., Del Popolo, F., \& Paixão (2009). Afrodescendentes en América Latina y el Caribe: del reconocimiento estadístico a la realización de derechos. Santiago de Chile: CEPAL.

Bejarano, J. P. (2010). Qual a sua raça ou grupo étnico? Censos, classificações raciais e multiculturalismo na Colômbia e no Brasil. San Salvador: UFBA.

Bertalanffy, L, V. (1976). Teoria Geral dos Sistemas. México: Fondo de Cultura Econômica.

Blog Afrocensos (2010, 17 de outubro). Epsy Capmbell fala sobre Censo 2010 [entrevista]. Disponível em https://www.geledes.org.br/epsy-campbell-fala-sobre-censo-2010/

CEPAL (2005). Seminarios Pueblos Indígenas y Afrodescendientes en América Latina. Santiago de Chile; Naciones Unidas: CEPAL.

CEPAL (2008). Censos 2010 y la Inclusión del enfoque étnico: Hacia una construcción participativa con pueblos indígenas y afrodescendientes en América Latina. División de Población. Santiago de Chile: CELAD; UNICEF; Fondos de Población de las Naciones Unida; Comisión Estadística de la Américas de la CEPAL.

CEPAL (2009). Afrodescendientes en América Latina y el Caribe: del reconocimiento estadístico a la realización de los derechos. Santiago de Chile: CEPAL.

CEPAL (2011). Recomendaciones para los censos de la década de 2010 en América Latina. Santiago de Chile: CEPAL.

Conferência mundial de combate ao racismo, discriminação racial, xenofobia e intolerância correlata (2001). Declaração e Programa de Ação. Brasília, DF: Fundação Cultural Palmares.

Costa, S. (2003). Redes Sociais e Integração Transnacional: problemas conceituais e um mundo de estudo de caso. Política e Sociedade, (2), 151-176. 
Costa, S. (2006). Dois Atlânticos: teoria social, anti-racismo, cosmopolitismo. Belo Horizonte: UFMG.

CRI (2006). Articulação para o Combate ao Racismo Institucional. Identificação e abordagem do racismo institucional. Brasília: CRI, 2006

Ferreira, F. H. G, \& Walton, M. (2005). Desigualdad en América Latina y el Caribe. ¿Ruptura con la Historia? Washington: Banco Mundial. Disponível em http://documentos.bancomundial.org/curated/es/916491468046165704/pdf/3485609586 82541rica0Latina110PUBLIC.pdf

Hall, S. (2006). A identidade cultural na pós-modernidade (Trad. Tomaz Tadeu da Silva e Guacir. e Guarareira Lopes Louro). Rio de Janeiro: DP\&A.

Instituto Brasileiro de Geografia e Estatística (2011). Censo Demográfico 2010. Características étnico raciais da população: um estudo das categorias de classificação de cor ou raça 2008. Rio de Janeiro: IBGE, 2011.

Maya, J. A. (2007, junio). Los negros ingleses o creoles de Honduras: etnohistoria, racismo, y discursos nacionalistas excluyentes en Honduras. Revista Sociedad y Economía, No. 12, junio, 115-129. Colombia: Universidad del Valle Cali.

ONU (2001). Declaración y Programa de Acción de Durban. Conferencia Mundial contra el Racismo, la Discriminación Racial, la Xenofobia y las Formas Conexas de Intolerancia. Disponível em http://www.oas.org/es/sla/ddi/docs/afrodescendientes_instrumentos_internacionales_de claracion_programa_accion_durban.pdf

Paixão, M. J. P. \& Carvalho, L. M. (2008). Censo e demografia: a variável cor ou raça no interior dos sistemas censitários brasileiro. Em O. A. Pinheiro \& L. Sansone (org.), Raça: novas perspectivas antropológicas. Salvador: Associação Brasileira de Antropologia (ABA): EDUFBA.

Sansone, L. (2004). Negritude sem etnicidade: o local e o global nas relações raciais e na produção cultural negra do Brasil. SciELO-EDUFBA.

Sant'Anna,V. (2009). Não deixe sua cor passar em branco. O que esperar do censo de 2010. Geledés. Disponível em http://www.geledes.org. Capiturado em 18 de abril de 2014. 